\title{
Myths and Realities: University Libraries
}

\author{
D. Kaye Gapen
}

This theme paper examines the current rate of change and makes projections of future rates of change in order to attempt a separation of myths and realities. The phenomenon of change is so pervasive in our literature and so ever-present in our daily lives that we must learn more effective adjustment techniques. In her "Law of the Situation," Mary Parker Follett proposes a continual process of reconceptualization of "what business you are in." The times require this of us. They also require that we examine "models" of change to use as appropriate. The Stages of Growth model is particularly appealing since it characterizes organizations as progressing through a series of stages along a continuum. As university libraries move along their continuum, it seems clear that as organizations they will become evolutionary, nonhierarchical, entrepreneurial, and horizontal. This growth sequence will require librarians to become more involved in the process of scholarly communication.

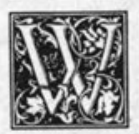

e are going to talk today about some myths and realities surrounding the present and future of academic libraries. We will be considering technology, the paradox of imaging the future, change, models for dealing with change, and personal and organizational characteristics that can help us decipher and deal with both the myths and the realities.

To set the stage, let me tell you a little story. I've been in Alabama now two and a half years, and during the course of this presentation you'll probably hear a few Alabamaisms; but this story was very popular a couple of months ago when we were getting a lot of rain in the South, and it may have even gotten some national press. In Louisiana, the rivers were flooding. A man was in his house, the water was coming up to the door, and some people in a rowboat came up. They said, "We'd like to rescue you; get into the boat." And the man said, "No, I trust in the Lord, I'm going to stay here." As the water kept rising, the people in the row- boat came back again and called, "Get in the boat; we'd like to save you!" And he said, "No, I trust in the Lord, I'm going to stay with my house." (The Deep South is in the Bible Belt, you know.) And so they came one more time, not in a rowboat but in a helicopter; the water was up to the roof, and the man was on the roof sitting there clinging to his chimney. The pilot said, "Sir, sir, come into the helicopter, we want to save you!" And he said, "No thank you, I trust in the Lord, I'm going to stay here!' Well, sure enough, he drowned. The water came right up over the top of the house, carried him away, and he drowned. He went up to Heaven, and he said to St. Peter, "Look, I want to know just what's going on here. I trusted in the Lord and I drowned." And Peter said, "Well, we sent you two rowboats and a helicopter." I'm sending rowboats and a helicopter today. So let's just take some of these comments in that vein, and know that we can trust in the Lord, we can test the myths and the realities, but there are some things that we can do, too, to af-

D. Kaye Gapen is university librarian at the University of Wisconsin-Madison 53706. She was university librarian at the University of Alabama when this paper was presented at the ACRL Third National Conference, April 4-7, 1984, Seattle, Washington. 
fect our own futures. Of course, this story tells us it is very important to know when to trust in the Lord and when to take the salvation that is offered.

Let me share a quote with you that is a little lengthy, but nevertheless important. "There is no need to expect that with the application of knowledge and skill things should always turn out right." [This sentence reminds me of my roommate in college who was a teaching assistant for freshman English for two years. She had a plaque in the kitchen that read, "You can be sincere and still be stupid."] "Instead there is a growing recognition that it is necessary and responsible to arrange all human and organization resources so that they are future-responsive, so that they act in the present out of a concern for the future, i.e., the task is to enlarge our awareness of what is happening and what might happen. This means becoming learners as persons and organizations. It means learning how to become learners, and to be learners we must become embracers of error.

"The competent person is one who designs his or her activities to provide the maximum amount of feedback about what is happening in order to detect and respond to errors. Competence, then, is measured not by skill in avoiding errors, but by skill in detecting them and in acting on that information openly so that all can continue to learn about where they are and where they might go-about what kind of world we have created for ourselves and what we might do toward recreating it. It follows that an equally central criterion of competence is the ability to facilitate learning error embracing, and awareness of one's self and others."

This statement comes from a book called Failures in Organization Development and Change, edited by Philip H. Mirvis and David Berg (New York: Wiley, 1977). The last fifteen years have provided an extraordinary learning experience in which we have had ample opportunity to facilitate learning and embrace error.

If we look back to the middle or late sixties and the early seventies, we see the implementation and development of the MARC format. The MARC format is a machine-readable, bibliographic format. It's the basis by which our records are numerically described and communicated. It's our primary communications format. The presence and refinement of that format allowed us to develop large online utilities: OCLC, RLIN, WLN, and so forth. And this, in turn, was paralleled by an increasing amount of cooperation and networking. The MARC format also has served as a basic communications and bibliographic format for our own online systems. Increasingly, we see either the implementation of online systems or some consideration and planning being given to the implementation of online systems in libraries: online catalogs, online circulation systems, online serials control, and online acquisitions. And, again, for states such as Alabama, there are more local networks and agreements.

In addition to local online library systems, we have also seen the growth and expansion of online database searching for reference service-both bibliographic and textual. We've seen interlibrary loan through the national bibliographic systems and now through regional and state cooperatives. We've seen growth, more recently, in video and audio-video technology that allows images to be transmitted digitally the same way as bibliographic information is transmitted. And, of course, one of the major changes that affected libraries directly has been the implementation of AACR2, a cataloging format that was developed and designed clearly to integrate cataloging more effectively into a computer environment. It is likely that we will see continuing changes in our cataloging and subject classification standards if we are to be responsive to what we are learning about the online environment and user patterns.

We have seen, therefore, significant changes, and we've seen the rate of change accelerating every year. We've seen changes in library job skills both for people presently working in libraries and people coming into libraries; we've seen the level of responsibilities change, particularly in the support staff positions. We have increased responsibility, changed job descriptions, and upgraded positions. 
We have paid for those upgraded positions primarily by cutting out lower-level clerical staff positions. And so what we often have in many academic libraries is fewer people, but at a higher level of responsibility. The nature of work that is expected of the professional librarian has changed, too, moving toward management, planning, and the more difficult cataloging and reference tasks.

We've also seen some changing organizational patterns, and I believe that we will see more. We have seen responsibilities combined with people moving from specialist to generalist. We have seen changing regional and cooperative patterns and, increasingly in the last five years, the growth of economic and legal concerns related to networking and cooperative development.

We know from our experience what change is and how we feel as we face change, act it out, and are acted upon by it. It would be useful, however, if we had a more formal definition. This one comes from Gordon L. Lippitt in a book called Visualizing Change: Model Building and the Change Process (La Jolla, Calif.: University Associates, 1973): "Change is any planned or unplanned alteration of the status quo in an organism, situation or process; and planned change is an intended, designed, or purposive attempt by an individual, group, organization, or larger social system to influence directly the status quo of itself, another organism, or a situation." Organizational change is "any planned or unplanned alteration of the status quo which affects the structure, technology and human resources of the total organization."

Today we are going to try to answer the question of what we will do with change in academic libraries and how much of it is myth and how much reality. Based upon my experience as a library director over the past three years, I believe that in the future, it will be the individuals, the groups, and the organizations that, by manipulating their physical and social environments, by contributing to planned change, by coping with obstacles and persisting toward their goals, will tip the scale toward continuing the viability of librari- anship and, indeed, the betterment of humankind. Those who are less adventuresome will be easily sidetracked or defeated by obstacles and will become victims of change.

In the presentation today, first we will look at the future and decide whether or not we can separate the myths from the realities. Second, we will ask ourselves the questions posited by Mary Parker Follett's "Law of the Situation" in order to do a little reality testing. Third, we will talk about whether or not there are "models" of change that might be of use to us in working through ever-constant change. Finally, we will examine some of the beginning strategies for implementing planned change.

\section{THE FUTURE: MYTHS AND REALITIES}

Let us begin by looking at the future. The following statement is made in Failures in Organization: "The secondary and tertiary consequences of the interactions of technology with the rest of society make predictions of the impact of all externalities impossible. . . . We are unable to control the processes of change, and we are unable to predict the consequences of our efforts to control them."

On the other hand, we have the story of the ninety-year-old couple who went to a lawyer to see about getting a divorce. The lawyer was surprised and asked why such an old couple was getting a divorce. The couple replied, "We have been having trouble for a number of years, but we wanted to wait until the children died."

We are faced with the very real paradox that when the future occurs it will be real, but today the future is a myth. At the same time that we know we cannot predict what is going to happen, we feel that we can wait too long to act and that all of our ideals and hopes can die before we act. In our daily lives then, we try to do both. Later I will discuss how models of change can help us meet the future, since we cannot predict its reality. I will also share with you an exercise in selecting among the various myths. We will try to "image the future."

I've had four opportunities in the last 
year to do some forecasting for the future of librarianship. The first one occurred last summer at UCLA, where I attended a sixweek program at the library school with eleven other librarians. We had an opportunity to do some research and talk about some of the basic problems and challenges in libraries today. I am going to share some of that with you regarding possible courses of action in libraries. The second opportunity I had was an evaluation meeting of the Bibliographic Services Development Program (BSDP), which was funded by the Council on Library Resources. The evaluation of the BSDP program, which is occurring this year, is designed to assess what has happened to date in bibliographic control and networking and to establish priorities for the next two years. The third opportunity was with an ad hoc committee of OCLC ARL librarians coming together to make a beginning attempt at formulating the most important thing for research libraries in terms of OCLC development. And, finally, we will quickly review some of the strategic planning that OCLC is doing, looking ahead into the future.

I want to share with you, first, a generalized look at the future that is broader than the library-specific world, but brings in many elements that I think we will find common to our own experience and that parallels much of what the future of libraries might contain. I am reading, in the course of working on this models-forchange idea, a book called Megatrends (New York: Warner, 1982). The author, John Naisbett, talks about major trends in the world today.

The first major trend is that we have moved from an industrial society to an information society. We have a waning economy based on the industrial society, but we have a developing economy based on information.

The second major trend is that we are moving from forced technological change to the infusion of high technology that is combined with "high touch." And I will come back and tell you what he means by high touch in a moment. Third, we are moving from national economies to world economies. Fourth, we are moving from the concept of centralization to the concept of decentralization, with these trends existing not only politically, but in our corporate business world, our religious structures, and our social institutions. Fifth, we are moving away from the concept of institutional help to the concept of self-help. Sixth, we are moving from a representative democracy to a participatory democracy. Seventh, we are moving from the concept of hierarchies to the concept of networking. Eighth, we are moving from the North to the South. And, finally, we are moving from the either/or situation to multiple options in terms of what we can do as people and what we can do as corporations.

The following are some of the specific points that Naisbett made. We can think of examples throughout that would carry these concepts into libraries.

The new wealth is know-how. We are in a transition between economies, and entrepreneurship is booming. The growth of small businesses is also booming. The information society is an economic reality. There are innovations in communications and computer technology that will accelerate the rate of change by collapsing the information flow. The information flow is how long it takes somebody to find out something. Today, you can know five minutes after something's happened on the other side of the world that it has occurred. And that's having an enormous impact on communications and the rate of change.

New information technologies will first be applied to old industrial tasks, then will gradually give birth to new activities, processes and products. In libraries, we've seen the new technology applied to old bibliographic tasks, but now we're going to see emerging databases and approaches to access that we haven't really envisioned before. In this literacyintensive society, when we need basic reading and writing skills more than ever before, the education system is turning out an increasingly inferior product.

The technology of new information is not absolute. It will succeed or fail according to the principle of high tech/high touch. High touch concerns the fact that 
we like being together with other people. We do not like dealing only with machines. So as we increasingly rely on high technology, at the same time we ask people to play a greater role in what we are doing. We are drowning in information, but we are starved for knowledge. We have so much information floating around that people don't know what to do with it.

We are moving from the specialist who is obsolete to the generalist who can adapt. We must learn to balance the material wonders of technology with the spiritual demands of human nature. Again, we need to be together as people. Strategic planning is going to become an increasingly important tool, but strategic planning is worthless unless there is first strategic vision. We are building from the bottom up. People whose lives are affected by a decision must be part of the process of arriving at that decision in politics and in corporations.

Change occurs when there is a confluence of both change in values and economic necessity, not before. Hierarchies remain, but our belief in their efficacy does not. More and more we are thinking that the hierarchical organizational patterns of the industrial age are not appropriate to the things that we are doing today. Networks are people talking to each other, sharing information, ideas, and resources, and the important thing is not the networking but the process of getting there. (Many of the points that are made in Megatrends are also made in another new book called In Search of Excellence (New York: Harper, 1982), which talks about the same thing-major corporations that have continued to demonstrate excellence because they have a different set of values and a different set of operations than we have seen in the past industrial, hierarchical age.) We will restructure our businesses into smaller and smaller, more entrepreneurial, more participatory units.

Megatrends concludes with the observation "that the computer will smash the pyramid. We created the hierarchical, pyramidal, managerial system because we needed it to keep up with people and the things people did. With the computer to keep track, we can restructure our institutions horizontally."

Now that we have set the larger stage, what were the results from some of the other groups that I mentioned? We will start with UCLA. The Management Change subgroup arrived at four principles that we felt were going to be important. First, organizations in the future have to be fundamentally flexible, they have to be scientifically skilled, they have to be actively proactive, and they have to be profoundly people-oriented. After exploring some basic principles, we next talked about steps that had to be taken in the next five years in terms of the library's major administrative functions. I'm not going to tell you all of the things that we had forecasted in any of the major functions but, instead, will share selected parts with you. Under plant, we will undertake, in the next five to ten years, a strategic review of plant utilization and remodeling. We will remodel facilities as required for the maximum utilization of technology. Under staff resources, we will reorient all staff at all levels with the changing nature of libraries and information networks. We will develop programs for the regular, periodic reassessment of librarians. We will enlarge the responsibilities of librarians with much more outreach. We will increase the educational requirements for librarians. We will increase the proportion of the support staff at the upper levels, which means we will probably continue the trend toward fewer people, but with higher classification of job responsibilities. We will make staff at all levels computer-literate, we will increase the use of part-time and work-at-home personnel at the lower levels. We will strengthen the collegial nature of library faculty. We will expand and strengthen staff development programs. We will undertake periodic full review of all library positions and classifications. Under budget, we will establish a new budget criteria category for access costs; that is, we now, most of us, charge people for online searches, at least for the cost of the search if not for the cost of the staff support. We think the likely trend will be that library budgets will be allo- 
cated to pay all costs, and that allocation will occur through discontinuing some of the paper subscriptions and substituting full online access that the library will pay for. We will develop ongoing outside support for traditional library collections. We will develop a balance sheet and other accounting instruments for library and campus information resources. We will work the cost data into campus information policy. We will obtain approval for ongoing programs for amortization of library equipment.

Under information resources, we will install marketing programs for online text acquisition and electronic journals supplied through the library. As faculty members and students have a greater opportunity to go directly to the information databases, outside of what has been traditionally found in the library books and journals, we want the library to be a part of that chain. We will increase expenditures for access services and for nonbook materials. We will begin and expand the telefacsimile and its offspring. We will provide for more precise responsive subject specialization. We will revise collection development policies in light of changes. We will utilize optical videodiscs for building collections and for preservation, probably phasing out the purchasing of microforms as other formats are substituted.

Under services, we will phase in nocharge database services for our primary clientele. We will inaugurate a campus document delivery service that can provide both physical documents and telefacsimile transmission. We will provide twenty-four-hour-a-day physical access to resources and selected services of the library. We will provide remote online access to resources and services. We will investigate and add new information services. We will insure library participation in planning and installation of local area networks on campuses. We will incorporate the "special library model" in planning and evaluating library services. Basically, the special library model is a phrase for what special libraries are able to do in working with specialized clientele, in knowing their interests and your re- sources so that you provide the information rather than the access to the bibliographic description.

Under organization, we anticipate that we will loosen the library organizational structure. We will increase the acceptance by the library director and staff of uncertainty and risk. We will be more aware of the importance of mentoring. We will expedite decision making at the lowest possible levels.

Now let me move on to the BSDP review meeting. We thought that BSDP should address, first, networking at the national level, so that we have some way of establishing the computer links for our separate databases. That means that not only can OCLC's computer talk to the Library of Congress, but that Dickinson's computer can talk to the OCLC computer or to the Library of Congress. Through those technical links, we would have access to resources that we now can only dream about. That is one of the first BSDP priorities.

The second is that librarians, through their own work and the work of leadership groups such as the Library of Congress and the Council on Library Resources, would begin to develop models of the electronic campus that include the integral role of the library in information transfer. The electronic campus, or wired campus, is not as good a descriptive label as we need. What this means is that as campuses face the need to communicate more effectively, we are going to establish cable networks from office to office to classroom. Those cable networks, which are now called local area networks (LAN), will also be part of telephone systems so that people in the classroom can go to the library computer or can go outside to other computers. Those LANs will transmit, not only word processing information on campus, but a more effective electronic mail delivery service. We will see an increase in communications and a decrease in the amount of paper. Eventually there will be broadband networks that will also allow us to transmit video images. That means our online catalogs will also have a component for storing our bibliographic 
information, our catalog records, and the content of our collections and catalogs on videodiscs. When that occurs, people can access the images on that videodisc in the office or in the classroom. Libraries have been ahead of the game in terms of some of these high-tech developments, and we can build on that and grow if we are proactive.

The ad hoc committee of OCLC ARL librarians arrived at similar prioritiesnational networking and the ability to make the library a part of a LAN on the campus.

And, finally, OCLC has been working on strategic planning and thinking about the future. I would like to share a few of these areas with you:

1. videotex

2. telecommunications networks

3. electronic mail

4. facsimile transmission

The implications of this imaging are many. In considering further which might be myth and which reality, I would like us to consider an excellent question described in Megatrends. Mary Parker Follett was a business consultant in the early 1900s. She proposed the "Law of the Situation." In applying this law, you ask yourself what your business really is. When a situation changes, you do one of two things: you reconceptualize what business you are in, or you conceptualize what business it would be useful for you to think you should be in. When change is constant, this reconceptualization also has to be constant.

And if we look at what we have done in libraries and what our image is of the future, I would put to you that we have been in the package delivery system. We have stored and delivered books. Application of the "Law of the Situation" tells us that the next level of business for us is the information delivery business. And that means we will do some things very differently than if we were in the package delivery business. We are in transition from one to the other. And there's room for great entrepreneurship.

When I made this point at a meeting not long ago in Pennsylvania, Joan Bechtal from Dickinson College said that even more important than information delivery may be the fact that we are in the "conversation" business-facilitating scholarly and other conversation.

So we have the future and all it might hold. We know from our experience thus far that the implementation of technology and other changes sometimes results in very real personal and organizational concerns and problems. At Alabama over the past three years, we have been going through a number of significant changes, partly in order to try to "meet the future" and partly to address the present. I knew that there had to be techniques for structuring and facilitating change, but we were all so busy killing the snakes that we didn't have time to plow the field.

One of the things that we were supposed to do in the work at UCLA was some sort of research. I decided to see if there was a way to address more effectively the changes being implemented in libraries. The major point to consider here is that while the future is a combination of myth and reality that can only be directly addressed as it arrives, we can practice a very substantial reality by developing ourselves and our organizations in order to be future-responsive, so that we act in the present out of a concern for the future, so that we can become learners and embracers of error. I want to share with you the work that I did on models of change, realizing that it's much harder to do it than to talk about it.

If we look at change and models of change, we see a wealth of literature in the social sciences. Building a model of an activity or happening is useful in that it provides us with a conceptual framework for thinking about some complex interrelationships. A model defines. It has to be symbolic representation of a lot of layers of complex activity. A model of change has to be able to detect multiple causation within the forces that are involved and the complexities that exist. A dynamic model of change must indicate the forces influencing the situation over a period of time, and it has to have feedback loops.

A change model will be goal oriented, and the results of the application could and should be evaluated. The function of 
the model is heuristic in the sense that it has to be adapted by experience during the course of its applications. In this way, the model can grow as your own experience grows.

I am going to share with you some of the models I uncovered this past summer, including a very interesting organizational model, and list some of the individualoriented personnel models. The purpose of each of these models is to describe and guide the dynamics of change for both people and organizations. With a set of these models in place, it is possible to be future-responsive, proactive learners in dealing with change. We can organize so that we respond to change no matter what that change is. This is the essential reality. We can review past decisions in order to enlarge our current options by asking the proper questions. We can analyze our past errors in order to provide contingency plans for future action. And finally, we can emphasize looking ahead and not looking back. We do not have to be content with monitoring our environments; rather we will search them through longrange planning and through internal and external feedback processes. We will be more likely to know who likes whom, how, and why; what emotions are likely to be felt depending upon the hat being worn; and what levels of participation are likely to result in successful organizational and personal life.

At UCLA we spent most of the six weeks discussing how to change and how to get people to change. The most basic division of thought had to do with how much people could participate in decision making, how much responsibility they could be given, and when one led and when one pushed. Every day we used some "model of man," or perhaps several models. We employed some notion about what a man or woman is and how he or she works. Whether we made our models explicit or not, we did form expectations about how others behaved toward us or would respond to something we did. We were not aware, in the beginning, that this phenomenon was described in the literature.

What is emerging in present behavioral science studies is an open system model of man. There is no one proponent or hypothesis for this particular concept, but the major thrust of such a model is the transactional nature of people-rather than being passive agents reacting to stimuli, people are viewed as active and proactive agents, purposive in nature and problem-solving organisms. Also, in this model, each individual selectively perceives and interprets the influences of environment and the configuration of different factors and forces. This is not the model that is traditionally characteristic of the industrial age and its hierarchical organizations.

While finding out about this open system model of man did not exactly resolve our UCLA disagreements, it was a real eye-opener for me. With a model of the individual in place, the question of further model selection and approaches to change fall much more readily into place. This particular model of the individual is exemplified again and again in In Search of Excellence.

With this in place, then, I would like to share with you, first, an organizational change model called the Stages of Growth model. This model seems especially appropriate to the context that I have been building in the course of this speech in that the model characterizes organizations as progressing along a continuum of stages of growth. There are two kinds of managerial approaches that affect the organizational growth: steady state and evolutionary. Steady-state management is one in which you have an operations basis of strategy. You look at what you are doing right now and just try to do it better. Growth with this strategy is limited. Evolutionary, entrepreneurial management, on the other hand, takes the strategic approach, which considers current operations as one part of overall growth strategy that can encompass the possibility of diversification through acquisitions into other businesses as well as investment into existing operations. Other components of the model include single or multiple and related or unrelated services or products. Basically, however, growth along the continuum is characterized by diversification (or movement into multi- 
ple product lines) and by evolutionary, entrepreneurial management with a rich and varied strategy. This sort of movement emphasizes a different organizational approach to management, which departs dramatically from the traditional pyramid of control. While the success of this approach results somewhat from the environment, the managerial factor is pivotal in the change process described by this model. This description-modelseems to me appropriate to our present library environment and describes how we might control and direct change.

What are some of the other models that apply more specifically to individual as opposed to organizational growth? This is basically a list, but you can get a feeling for their tenor. There is a model for human resources development that brings together what happens for the individual, what happens for the organization, what happens for groups within the organization, and what occurs in the interaction between those forces. There's a model for management development. There's a problem-solving model that incorporates the participation of all the people in the organization in dealing with the problems, demonstrating how to build goals for the future. There's a model for describing elements in the helping process; that is, how we as humans deal with one another and help one another grow within the corporate environment. There's the model that we all know about-Theory $X$ and Theory $Y$. There's a group-change model, and there's another one called the framework for planned organizational change. All of these models are realistic and appropriate to our present and future library environments.

Let's come back to some specifics. We are information workers, and we are right there in the forefront of the information society. In high technology, we provide the high touch. Most of us who work in public services and who interpret the library for people are the high touch. Those of us who work in technical services are high touch, but in a slightly different way. Faculty members and students will continue to look to us for high touch as long as we will take the role of providing it. I think our greatest possible competitors are companies that will begin to provide information and will be very adept at using people in addition to the high technology. But for today, libraries are high touch. We also bring a consistent humanistic commitment to the provision of knowledge. We have always believed in the provision of information regardless of the ability to pay, and that's an issue of growing ethical importance as are the continuing concerns surrounding censorship. Libraries will continue, but the "Law of the Situation" suggests that their nature will change. Library organizations will become evolutionary, nonhierarchical, entrepreneurial, and horizontal. All this means that each of us will participate more in discussions and decisions. We can be the centers for scholarly communication, the organizers, and we will be the people who provide the special library's model service to the campuses that we serve. Everyone in this model will have greater responsibilities and greater accountabilities. And that will continue to change also. As you participate, your responsibility to participate grows, and it just keeps cycling upward.

Our organizational units will head toward generalization rather than specialization. And eventually, we may all be organized along the lines that Hugh Atkinson at the University of Illinois keeps talking about: the primal tribe. His position is that groups of people larger than twelve usually don't get along very well, but that a group of twelve or smaller is just large enough to provide some excitement, and not so large that you can't do some changing.

Some management techniques will change. We will have long-range planning, I think, in all libraries in the next five years; this will occur from the bottom up and the top down and come together in the middle. That long-range planning will allow us to buy the future in a way that we do not now. And a key point that is made in all of the reading I have done so far is that American business strategy has been short-range (profit-oriented) rather than long-range ("developing the corporation 
in order for it to be more productive in the future" $)$. When I consulted at Dickinson College in 1979 on what they were going to do with their online catalog, I told them, "Don't develop your own catalog, buy somebody's-buy the software, buy the hardware." You'll have all kinds of trouble with the computer center, it's expensive to develop, and all of that. This last year, as I have put together these thoughts, it seems to me that the most important thing that librarians can do in the next year to two years is to have the closest possible relationship with their computer centers. Presidents of institutions look at two areas on their campuses when they have to spend big bucks: they look at computer centers and they look at libraries. And if we have to fight with the computer center for resources, we are probably going to lose. If we can have close relationships, we are more likely to succeed together. Now, for a variety of reasons, Dickinson is working with the computer center to develop their system. Joan Bechtal said, "You're probably going to think we've had to do the wrong thing." My feeling is that it has ended up as a savvy, long-range collaboration that might set the stage for the computer center and the library together to become the information providers for the campus. It's a logical way to look at the information resource allocation, and it's the best kind of arrangement to develop into the information society that we've been talking about. That kind of long-range planning will be very different from what we've done in the past and will require some short-term decisions that differ markedly from those we have been making up to this time.

Further management improvements will induce budget allocation models that will be different from what we use now. We will have a different way of looking at our job descriptions and other personnel concerns. In the past, most library job descriptions have been contained within the library. I think we are already seeing more and more job descriptions for career staff people, and sometimes even faculty members and librarians, that relate to other information people on campus. I think we're going to see much more across-theuniversity job description going on, and we need to be very active in describing clearly and accurately our job responsibilities and performance standards. We will see a difference in evaluation. There will be higher standards for evaluation, I believe, because we're going to be paying more and we're going to be working at higher levels of responsibility. We will participate more in those evaluations, and the evaluations will probably be more realistic. We're entering the time when in higher education we've got reports such as A Nation at Risk, which is demanding greater professional accountability. We, the people, the taxpayers, are demanding that teachers teach better. That kind of accountability is going to spread into other public service areas, so that accountability for us is going to be a higher prerequisite.

Staff development is going to become increasingly important. We're going to look at education and our own development in our organization as a lifelong learning process. I think we are going to see more seminars on time management, stress management, computer literacy, wholeness, the ability to listen, and so forth.

Research will become even more important. We have to be able to buy the future by investing in future-orientation. Librarians have to put money into research in addition to what occurs in library schools and the work funded by the Council on $\mathrm{Li}$ brary Resources and other such agencies. Tomorrow's research needs to be information- and high tech-aware.

Our own human expectations will change. We're going to look differently at how we spend our time. I don't believe we're going to be "9 to 5 " much longer. We're going to look at the work cycle differently. We're going to work at the office part of the time, and I think we're going to work at home part of the time. We're going to look at productivity differently. I believe we're just going to have a more open view toward how we can increase productivity or how we can evaluate it. We're going to look forward, we're going to be more participative, and I believe we're go- 
ing to take more risks. Every person who works in a library is going to be taking more risks in the next five years. Stepping outside our comfortable hierarchies can be an uneasy move. The models will help us, but they can't do it all. We have to participate, we have to say what we think; we have to put some of our responsibility on the line and be assessed by the people we work with, and that's not so easy. We have to be open and show initiative and courage, and those are qualities that are difficult at times to develop.

The fact is that our cool models exist hand in hand with hot cognitions. Most models call for rational scanning of alternatives and the calculation of probable gains and losses-i.e., cool models. But hot cognitions result in limitations stemming from imperfect information, human impatience, and the difficulty of adding into our equations the emotional components of hope and fear, not to mention our unconscious projections and fantasies. There is no final resolution of our hot cognitions (for which we should probably be thankful), but it is important that they be right out there in the front as we assess our various models.

Now what does this mean in terms of some beginning strategies? First, librarians have to establish the Stages of Growth model for the university and the library. We are part of our universities and colleges, and unless we know how they're going to change, we can't be as active and reactive as we need to be. So we have to examine where the university is going. One path for public universities, for example, is in the direction of more cooperation with business-more specialized delivery of teaching and research resources. We see such a development in Alabama, and I think it is likely to spread. We have to adopt the appropriate management style, and I think in the case of libraries it has to be evolutionary and it has to be entrepreneurial. And all of us make that happen. We have to establish a strategic planning mechanism within the library to include present operational issues, the evolutionary management strategies that are going to develop, and management training and education. Staff training and education are important. We have to look at areas of diversification and ask that "Law of the Situation" question in departments and in the library as a whole. We have to establish evaluations and feedback loops, and we have to have an appropriate timetable. And we have to begin to do this today.

Knowledge about something does not necessarily mean that there will be some intelligent action or change. In change we usually find a situation that involves experimentation, risk, insecurity, challenge, fear, and courage. There is a need to recognize that change always involves a process of confrontation, which involves the areas of knowledge, skill, and values. We must recognize that planned change can take place in a number of different areas:

1. Knowledge change area-generalization about the change experience, cognitive or conceptual understanding about the change.

2. Skill change area-the incorporation of new ways of performing through practice of the changed behavior.

3. Attitude change area-adoption of new feelings through experiencing success with them.

4. Values change area-the adoption and rearrangement of one's beliefs (need for confrontation, search, and coping).

In conclusion, let me share with you one last thought. You and I as people are our most important assets. In the book The Universal Traveler, A Soft Systems Guide to Creativity, Problem Solving and the Process of Reaching Goals (Los Altos, Calif.: W. Kaufmann, 1976), we are told how we can learn to be creative thinkers. You may not think you're very creative, but creativity and looking toward the future are learnable and valuable skills. We can be creative people, creative thinkers, creative changers. There are five steps toward developing creativity.

The first one is self-discipline, or freedom from pride. Pride is used here as a general term for the hang-ups associated with the lack of self-discipline. To be able to hold your head up high is countercreative behavior. To be concerned about change is equally alien. Both are traits that 
detract from the positive attainment of goals.

The second step is the belief in one's ability to succeed. You simply need to be confident and to go on regardless of what happens.

The third one is constructive discontent. You have to be careful with this one since it is right on the borderline between destructive and constructive. But constructive discontent is very positive.
The fourth is wholeness. And we're beginning to see much more emphasis on and understanding of wholeness today. It's everything that we sense and know and how we approach things-what's our view of life, what's our view of people?

And the fifth step is the ability to escape from habit. There are good habits and bad habits, and we need to review all of them in order to escape from the bad habits and keep the habits that are good. 